\title{
Supplier Satisfaction with Public Sector Competitive Tendering Processes
}

\author{
Abstract \\ Purpose: This research explores the supplier perspective on competitive tendering processes \\ and builds on an increasing and developing interest in supplier satisfaction with public sector \\ procurement activities. \\ Design/methodology/approach: Qualitative data was collected from 20 interviews with a \\ variety of suppliers to the UK public sector, which was then analysed using Nvivo and a \\ series of empirically supported propositions developed.
}

Findings: Our findings are combined into an integrated supplier satisfaction model, which explains how a multi-layered set of expectations (past and ideal) and quality dimensions (fairness, ambiguity, unnecessary information, tender focus, relationship irrelevance, unresponsiveness, outcome success) lead to dissatisfaction. We also establish the implications of these judgments (non-response, poor quality and relationship impact) and that they are impacted by comparison to alternatives.

Practical implications: Supplier dissatisfaction can have serious ramifications for public sector buying organisations by reducing the pool of applicants, creating relationship barriers and a disconnect between the tender and the eventual services provided. We give empirically derived advice to managers and policymakers on how to avoid these issues.

Social implications: Ensuring that as wide a pool of possible suppliers can respond to tender requests, means that the services that are provided by the public sector can make the most effective and efficient use of available resources. In addition, SMEs may be encouraged to overcome their feelings of dissatisfaction and respond more frequently and readily to tender requests. 
Originality: We contribute to the field of public sector procurement and in particular that which looks at increasing supplier satisfaction, by developing a supplier satisfaction model based on supplier generated data, which uses disconfirmation theory to explain the dynamics of how individuals make judgments by comparing perceptions of performance with a multilayered set of expectations. We identify service quality dimensions that influence satisfaction judgments and the implications of these judgments.

Keywords: Competitive tendering process; supplier satisfaction; public sector procurement.

Article classification: Research paper

\section{Introduction}

In Organisation for Economic Cooperation and Development (OECD) countries, public procurement spending represents $12 \%$ of Gross Domestic Product (GDP) (OECD 2017). In the United States (US) it is over 9\% (OECD 2018) and in the European Union (EU) approximately 14\% (European Commission 2018). Total spend figures are also significant, with the US government spending $\$ 473$ billion in 2016 (USA Spending 2018) and the EU €2 trillion in 2015 (Europa 2018). Unsurprisingly, governments are under pressure to manage their spending in the most effective and efficient manner. For example, a one percent decrease in expenditure would mean $€ 43$ billion per year of cost savings across the EU (OECD 2018). If countries decrease public procurement spending by $10 \%$, through improvements in efficiency while buying the same goods and services, total government expenditure across OECD countries could be reduced, on average, by $2.9 \%$, resulting in a $56 \%$ reduction in government deficits (OECD 2018).

Public procurement refers to the process where public authorities, including all levels of government and public agencies, buy goods and services or commission work and includes 
the purchase of anything from telephone services to private financial initiatives (Uyarra and Flanagan 2010). Competitive tendering is an essential part of the public procurement process, aiming to increase competition by inviting suppliers to express their interest in bidding for contracts while allowing buying organisations to procure goods and services by evaluating and selecting the most appropriate supplier. Since tendering is an early stage of the procurement process, it provides a foundation for inter-organisational relationships, and perceptions of actions and behaviours at this early stage affect how buyers and suppliers treat each other at later stages.

Suppliers are not bound to supply only the public sector, as private sector suppliers meet the needs of a variety of buyers across the public, private and third sectors. If they are repeatedly frustrated and become dissatisfied with the competitive tendering process of public sector buyers, they can stop supplying to the public sector and focus their efforts elsewhere (Schiele, 2020) and could limit choice of supply, increase costs and limit efficiency in the public sector.

The public sector competitive tendering process is not without criticism. Examples range from the negative impact of tendering on customer satisfaction in public transport (Mouwen and Rietveld 2013) to tendering leading to a complex mix of public good and market rationalities (White 2014) and that the process is badly designed and executed (Lega et al., 2013). Additionally, productive buyer-supplier relationships can be severely negatively impacted in the competitive tendering context, for example, it has jeopardised connections across local health-care pathways (Forrester et al., 2015) and poorly executed tendering led to the scrapping of the West Coast rail franchise award by the UK Department for Transport (BBC 2012).

To streamline public procurement and create a more service-oriented public procurement system, organisations need to develop clear and integrated tender documentation 
that is standardised, where possible, and proportionate to need (OECD 2016) as well as engaging in "upstream marketing" to promote their organisation with their suppliers and increase its attractiveness (Schiele, 2020). The US National Institute for Government Procurement (NIGP) advocate ongoing dialogue throughout the procurement cycle to generate value-added activities and services (NIGP 2013). To achieve this, organisations need to shift from a buyer-centered focus to one where the supplier is seen as more than just a static recipient of the tendering mechanism and that suppliers are motivated to spend time and effort in participating. This perspective reflects a trend within supply chain management (SCM) literature, exploring the benefits of collaborative buyer-supplier relationships to improve organisational performance and outcomes (Cadden et al., 2015). In addition, it is closely aligned to the buyer attractiveness literature (e.g. Hald et al., 2009), which involves buyers competing for suppliers, not just vice versa (Schiele et al., 2012) and reflects a more recent interest in satisfying suppliers in the public domain, as doing so will ensure that they provide better prices, more innovations and priority in bottleneck situations (Schiele, 2020).

In order to understand supplier perceptions beyond simply establishing whether they are satisfied (or not) with competitive tendering processes, we have developed a theoretical model of supplier satisfaction, which is based on concepts from the satisfaction and service quality literatures. We adopt a typological approach (Delbridge and Fiss 2013) by categorising and clustering ideas and offering a multidimensional perspective of supplier satisfaction with the tendering process (Cornelissen 2017). Three aspects of the competitive tendering process are explored from a supplier satisfaction perspective: first, disconfirmation theory is adopted to understand how suppliers make satisfaction judgements through an expectation formation process; second, the service quality literature shows how suppliers make perceived quality judgements; before finally discussing the behaviours that dissatisfaction stimulates in suppliers. This research addresses the following research questions: 
RQ1. What role do expectations play in the satisfaction judgements of suppliers in the tendering process?

RQ2. What quality dimensions do suppliers use to make satisfaction judgements?

RQ3. What behaviours result from (dis)satisfaction with public sector competitive tendering?

Our research makes several contributions. First, we complement a more recent trend of adopting a supplier perspective (e.g. Di Mauro et. al., 2020), which is relatively novel in public procurement research. Second, we develop an integrative model (Cornelissen 2017) to better understand the multiplicity of supplier satisfaction judgements and outcomes adding to disconfirmation theory and the public procurement field, thus developing our understanding of supplier satisfaction and building on the work of Schiele (2020). For practice, we show that supplier behaviour, resulting from dissatisfaction can lead to significant negative outcomes for buying organisations and the public sector more broadly. Such consequences of supplier dissatisfaction can include a reduction in the pool of applicants, the creation of barriers to relationships, and a disconnect between the requirements detailed in the tendering documentation and the eventual services provided. Drawing on insights from the study, we provide suggestions for managers and policymakers to improve the tendering process and have a customer-centered approach to dealing with suppliers.

We structure the rest of the article as follows; first, the literature review explores public sector tendering and concepts from the satisfaction and service quality literatures. The research method details the qualitative data collection and analysis of a series of supplier interviews, before the key findings and discussion develop a supplier satisfaction model of the public sector 
tendering process. The article concludes by identifying key contributions to the academic literature and a set of recommendations for practitioners and policymakers.

\section{Literature Review}

The literature review examines the competitive tendering process in the public sector, finding an extremely limited tendering process literature and a lack of a supplier perspective in this research. We draw on disconfirmation theory and the satisfaction and service quality literatures to frame the supplier perspective, positioning suppliers as the recipients of a service and providing insight into the dynamics of supplier satisfaction.

\section{Problem formulation: Limited tendering research from a supplier perspective}

Many studies identify the differences between public and private sector buying, with Purchase et al. (2009) stating that the public sector has more complex and ambiguous goals, which are sometimes politically driven and have a greater requirement for accountability. However, irrespective of the drives and aims, in both public and private sectors, procurement is inherently processual, from specifying the product or service needed, to selecting a supplier or suppliers and then managing the ongoing relationship (Van Weele 2010). The focus of this research is on the early pre-contract stages of the procurement process, which involves how buying organisations provide the supply market with requirements, evaluate responses from suppliers and select suppliers to fulfil requests. Examples of research in this area are Pedraza-Acosta et al. (2016) who develop a multi-phase approach to tendering to identify the most suitable decisions using different criteria, comparing formulas for (Stilger et al., 2017) or environmental impacts on choosing the economically most advantageous tender (ParikkaAlhola and Nissinen, 2012). 
Organisations use competitive tendering to ensure that that there is a pool of competitive suppliers and that buyers receive the best possible price, quality and requirements from suppliers. Regulation of public sector procurement activities varies across countries and regions, with the US public procurement system being subject to many statutes and international agreements, including federal, state and local provisions. The Federal Acquisition Regulation, for example, aims for uniformity throughout the procurement process (Eckerd and Girth 2017). Broadly, these aim to deliver best quality, while promoting competition and procuring with business integrity, fairness and openness. Similarly, the EU operates a free market to encourage competition and value in public procurement and this is driven by the EU Procurement Directives. These enforce legal obligations in the public sector to encourage a 'level playing field' for suppliers. All suppliers across the EU have an opportunity to respond to bids through open tender. In addition, competitive tendering mechanisms are transparent and make it easier to prevent corruption through bribes or other benefits (Tadelis and Bajari 2006).

Despite its long history and significant scale, public procurement is still underresearched (Harland et al., 2019) and the tendering process is covered in a more limited manner (e.g. Bergman and Lundberg 2013; Forrester et al., 2015; Mateus et al. 2010; Mouwen and Rietveld 2013; Tadelis and Bajari 2006). Often the research in this area, driven by government policy, focuses on how to engage small to medium-sized enterprises (SMEs) (Loader 2013, 2015; Pickernell et al., 2011) and highlights the many barriers that suppliers face in engaging with buying organisations (Walker et al., 2013; Loader 2013, 2015). These include prohibitive resource demands needed to engage in the public procurement tendering process and the adverse impact of large volume contracts on SME suppliers (Loader, 2013). In addition to a limited body of literature, the majority of public procurement research focuses on the buyer, with only a more recent turn towards adopting the supplier's perspective (e.g. Di Mauro et al., 2020). In addition, a number of these supplier perspective papers use secondary data in the 
form of buyer surveys. For example, Pickernell et al. (2011) used data from the Federation of Small Businesses survey (2008) and Loader (2015) used data from a government online feedback facility. When suppliers are asked directly by the buying organisations to participate in surveys, even when anonymised, there is a strong possibility of social acceptability bias occurring (Ramsay et al., 2013), leading to skewed reporting. As supplier satisfaction is a relatively new area of research, survey data and the use of modelling (e.g. Jiang et al., 2008) tend to lack the richness and depth associated with qualitative data. Research in this area is important as poorly performed tendering processes have a detrimental impact on companies, especially SMEs (Land and Gaalman 2009) and also on buyer-supplier relationships leading to reduced value for both actors (Ramsay 2005; Ramsay et al., 2013).

Our research aims to follow the more recent trajectory in the wider procurement field and takes a supplier perspective (see, for example, Ramsay and Wagner 2009, Kleeman and Essig 2013, Loader 2015; Schiele, 2020). Guidance from the OECD, the EU and the NIGP suggests the tendering process ought to be viewed as two-way, service and dialogue focused. However, there is no research on what are the barriers or facilitators to this approach or if it is happening. A transaction happens when the buyer offers value and gives suppliers the opportunity to win a contract and future business. Throughout the tendering process, suppliers are investing financially (in terms of resources and opportunity costs) and emotionally (exhibiting a desire to win the contract and the subsequent effect on their well-being). By shifting to this transactional, service-orientated and customer perspective of the relationship between the buyer and supplier in the tendering process, the supplier's experience of tendering would seem to be of utmost importance and is the focus of this research.

Towards a conceptual model: Satisfaction and service quality literatures 
Recent work in the public procurement field notes that supplier satisfaction is a new concept of study and that: "Buying organisations are asked to apply a form of "upstream marketing", in which they actively try to promote their organisation with their suppliers and increase its attractiveness...to get access to better services from suppliers" (Schiele, 2020, p119). However, studies of satisfaction appear in many different disciplines (Hsu et al., 2009), but without a common definition (Giese and Cote 2000). For this study, we draw on one of the most commonly cited definitions: satisfaction is 'the individual's perception of the performance or the products or service in relation to his or her expectations' (Schiffman and Kanuk 1978, 14). There are several aspects of this definition that contribute to satisfaction and guided the division of the review into the following sections: expectations, perceived quality dimensions, satisfaction judgements and outcomes. We also consider satisfaction at distinct levels and propose a conceptual model adapted from Oliver (1981), due to its use in several research settings, demonstrating its versatility and because it allows the identification of the dynamics of satisfaction.

Expectations. The customer satisfaction and service quality literatures view expectations differently. In the satisfaction literature, satisfaction occurs when expectations reflect expected performance (Churchill and Suprenant, 1982). Expectations are viewed as predictions made by consumers about what they foresee as likely to happen during an impending transaction or exchange. In contrast, the service quality literature views expectations as desires or wants often in an ideal sense: what a service provider should offer rather than what they do offer. Satisfaction is a post-decision customer experience, while quality is not (Parasuraman et al., 1988). In the quality literature, expectations are normative standards of future needs that are unaffected by marketing and competitive factors (Boulding et al., 1993). Normative expectations are more stable and represent the service that the market-oriented provider must 
constantly strive to offer (Zeithaml et al., 1993). While studies identify several types of expectations, such as ideal expectations (Tse and Wilton 1988), desired expectations (Swan et al., 1982), predicted expectations and normative expectations (Prakash 1984), there is no one single concept of satisfaction as it is a complex phenomenon with context specificity.

Perceived Quality Dimensions. Related to satisfaction, service quality is defined as: 'the totality of features and characteristics of a product or service that bear on its ability to satisfy stated or implied needs' (Kotler et al., 2002, 831). To compare perceptions of performance, we use disconfirmation theory, which proposes benchmarks in the evaluation processes, namely cognitive or affective standards (e.g., expectations, desires, and norms) that individuals use. Word of mouth (Parasuraman et al., 1988), personal experience, individual characteristics, and understanding of the environment and task (Khalifa and Liu 2003) influence perceptions of performance. There is a wealth of literature on service quality, with many studies identifying service quality dimensions. Most notably, the SERVQUAL model identifies five dimensions: reliability, assurance, tangibles, empathy and responsiveness (Parasuraman et al., 1988), although further developments, such as the INDSERV model (Gounaris 2005) are regarded as more appropriate in business-to-business (B2B) company settings, but do relate to SERVQUAL. INDSERV has four quality constructs more related to process: potential, hard process (comparable to responsiveness), soft process (related to assurance and empathy) and output quality (similar to reliability).

Satisfaction Judgements. Customer satisfaction research also draws on disconfirmation theory (Parasuraman et al., 1988), which Mohr (1982) noted is founded on four constructs: expectations, performance, disconfirmation and satisfaction. The theory states that customer satisfaction results from a comparison of one or more comparison standards such as 
expectations and perceived performance. The customer is satisfied when they feel that the product's performance is equal to their expectation (confirming). If the product performance exceeds expectations, the customer is very satisfied (positively disconfirming). If it is below expectations, the customer will be dissatisfied (negatively disconfirming). The comparison between expectations and performance is the common thread running through the satisfaction literature (Anderson and Sullivan 1993; Tam 2004): satisfaction occurs as a response to the difference between what is expected and what is received.

Comparison of Alternatives. Once an actor has experienced the tender process and (dis)confirmed their expectations about the process, the actor will then compare their experience to possible alternatives, which will then inform their behavioural response. This stage is not included in the satisfaction literature but is found in the social exchange theory literature. The theory proposes that exchanges or relationships are entered into to achieve maximum gain (Thibaut and Kelley, 1959) and are judged by the achievement of rewards or avoidance of penalties (Emerson, 1976; Griffith et al., 2006). Although each actor in a relationship will compare their experience in the relationship to a standard or previous relationship in order to judge satisfaction or dissatisfaction (analogous to expectation setting), the comparison of alternatives happens after the experience has occurred and affects the subsequent behaviour of the actor (Argyle 1987; Homans, 1961; Lambe et al., 2001; Thibaut and Kelley, 1959). The actor compares the experience of a relationship to any alternatives on offer to achieve the best outcome. If, for example, the actor has no alternative, then taking part in a subsequent tendering process is imperative unless the actor wants to go out of business no matter how dissatisfied they are with the process. However, where the comparison of alternatives shows a more attractive arrangement, the supplier will choose the alternative. 
Therefore, we propose that the comparison of alternatives to the current tendering process will impact, and moderate, the relationship between (dis)satisfaction and the resulting behaviours.

Behaviours as a Result of (Dis)satisfaction. Studies of the outcomes of (dis)satisfaction vary depending on the context in which they are deployed. In the consumer satisfaction literature, the outcomes tend to be re-purchase intentions (Halstead and Page 1992), loyalty gain or loss (Cho et al., 2002), recommendations to other potential customers (Meuter et al., 2000) and positive or negative impacts on firm reputation (Nakibin et al., 2011). Stanworth (2012) showed how suppliers can influence purchasers' satisfaction through service quality. However, studies exploring the behaviours resulting from supplier (dis)satisfaction have not been conducted in this literature, to our knowledge.

Satisfaction at Different Levels. Satisfaction research has various units of analysis. It tends to focus on individual satisfaction in evaluating the consumption of a product or service: the outcomes rather than the process of exchange. Satisfaction is directed to the product, consumption, purchase decision, salesperson, store or acquisition (Giese and Cote 2000). Most studies take an individual transaction focus and often explore the association of quality with other attributes such as price and value (Hallowell 1996).

Moving from an individual to an organisational transaction perspective, satisfaction is defined as 'a positive affective state resulting from the appraisal of all aspects of a firm's working relationship with another company' (Maunu 2003, p 43). Similarly, Benton and Maloni (2005) cite satisfaction as an affective state experienced by suppliers reflecting an absence of exploitation by the buyer. Few studies have specifically focused on supplier satisfaction during the tendering process. Ramsay et al. (2013) examined the level of supplier satisfaction, behavioural intentions, loyalty, perceived value and responsiveness (Ramsay et 
al., 2013), while others focused on supplier satisfaction as an outcome of exchange (Benton and Maloni 2005; Essig and Amann 2009; Ramsay and Wagner 2009). However, these studies do not focus on the tendering process and are conceptual rather than empirical (e.g. Schiele $e t$ al., 2012).

Much of the satisfaction literature is concerned with the mechanics of how individuals make satisfaction judgements but is limited in how satisfaction is evaluated and what the outcomes of these judgements are. To get a full picture of satisfaction in a particular context, it is helpful to incorporate service quality dimensions into satisfaction models (McDougall and Levesque 2006). In this study, we suggest that suppliers have expectations based on specific criteria, they perceive the tendering process according to service quality dimensions and make a judgement through the disconfirmation of expectations and perceptions. This leads to a certain level of satisfaction and results in behaviours and outcomes dependent on these satisfaction levels. This leads to our initial theoretical model, showing the additional concepts reviewed above, shown in figure 1.

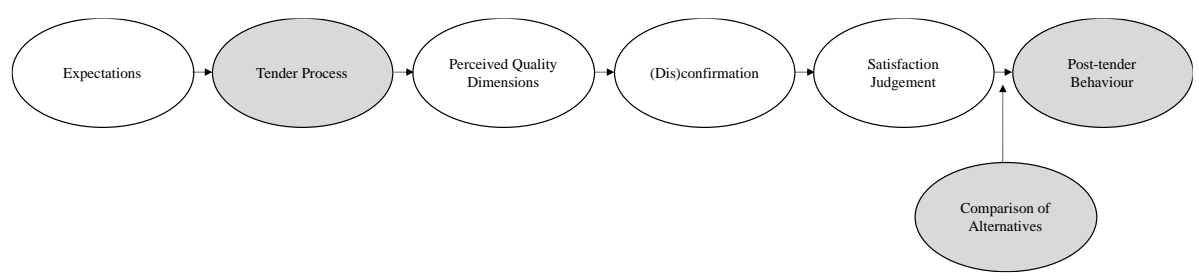

Figure 1. Supplier satisfaction model (adapted from Oliver, 1991 (shaded areas are new))

\section{Method}

Reflecting the nascent nature of this research (Schiele, 2020), an exploratory approach was necessary that was best suited to in-depth qualitative data collection. We conducted twenty open, unstructured, in-depth interviews with individuals from twenty suppliers involved in the public competitive tendering process. This allowed the researchers to uncover themes in the 
suppliers' perceptions of the tender process but maintained a focus on the research purpose and the general scope of the issues (Fife 2005). The interviews used general questions on the participant's perceptions of public sector tendering and what activities they engaged in when obtaining, evaluating and responding to them. Participants were asked about their experiences of a range of historical, as well as current, public sector tenders. The participants were identified by contacting buying organisations that had open tenders with publicly available information and asking for the researcher's contact information to be passed on. Trust was established by stating the researcher was not involved in any tender evaluation process and that their responses would be for academic research purposes only. This approach allowed for the provision of rich and complex descriptions of the tender process (Cavana et al., 2001). In addition, it allowed us to probe, with additional questions, for a deeper understanding increasing the validity of the research. After twenty interviews, theoretical saturation was reached, as no new insights were forthcoming. The majority of interviews were conducted by telephone, with two face-to-face and all were digitally recorded and transcribed within 48 hours of the interview.

Purposive heterogeneous sampling was adopted (Yin 2008), which captured a wide range of perspectives relating to the research questions. Companies were identified by contacting buying organisations that had current tenders open to the market and we selected multiple suppliers with distinct characteristics to capture a sample that had the variety inherent in the public sector supplier population. A number of selection criteria were used to ensure interviewees from a wide range of organisations were included in the study (shown in Table I) and included individuals who were directly involved in the tendering process. The interviewee job roles included Managing Directors, Commercial and Operations Directors, Bid Managers and Business Development Managers. In addition, the companies were selected from the noncritical, leverage and bottleneck quadrants of Kraljic's matrix (1983), as the size of most public 
sector buying organisations means that the spend thresholds required them to adopt formal competitive tendering processes. In addition, such items or services form a significant part of overall public sector spend, e.g. facilities management services were the UK's second-largest procurement category in 2016/17 (https://www.instituteforgovernment.org.uk/ourwork/policy-making/government-outsourcing). Strategic services tend to be limited to a small number of potential suppliers, often with multiple stage procurement processes and so are less commonly adopted and subject to standardised processes.

Insert Table I (Selection criteria for interviewees) here

The first phase of data analysis involved carefully reading all the interview transcripts and interview notes, to get an overview of the individuals, activities, functions and organisations involved. Data was entered into the qualitative data analysis software package, NVivo 11, to manage the large volume. Thematic analysis was performed, in which a firstorder analysis captured, verbatim, the individual's perceptions of the public sector tender process. This analysis identified factors that affect an individual's satisfaction expectations, perceptions, judgments and outcomes, i.e. the broad satisfaction-based themes we had identified from the literature. This was followed by second-order analysis where themes coalesced from a literal to a theoretical level. The interview data was deconstructing it into textual segments and coded within a node by using a descriptive term for each segment (e.g. 'wants to measure responses', taken from the participant's own language) and grouped into more abstract codes (e.g. 'comparability', to bring it to a theoretical level). We analysed each transcript in this way until the themes reached saturation. Therefore, in keeping with the exploratory aims of this research, the coding process was open and iterative, to capture the supplier's perspective on actual engagement with the competitive tendering process. We 
reflected on whether we needed to add or omit themes and codes and strove for inter-coder reliability. Coding was conducted by the primary researcher, and then after ten transcripts were coded, the team analysed a sample transcript and discussed any discrepancies in themes and coding. Once the coding process was clarified, the coding was completed by the primary researcher, and then again discussed at the end of the process to see if any themes and codes needed to be combined or separated.

\section{Findings}

The findings section takes each of the research questions and uses the supplier data to answer these questions.

\section{Expectations and Satisfaction}

RQ1 asked what role do expectations play in the satisfaction judgements of suppliers in the tendering process? Disconfirmation theory states that satisfaction judgements are based on the relationship between expectations and perceived performance. Our findings show that there are two types of satisfaction evaluation. The first satisfaction evaluation is anticipated or predicted expectations, where individuals (informed by their past experiences of specific tenders) compare their expectations with the performance of this tender process. Expectations are formed either from an earlier experience of competitive tendering with other organisations or experiences with a specific buying organisation. For example, respondents explained the process as: '[They will] see what you'll come up with really. Let's throw this out, a scatter approach and see what comes back' [Security 2]. Often this focuses on specific aspects of the tender documentation that cause dissatisfaction: 'sometimes the evaluation is very, very rigid 
in terms of the criteria' [Security 3] or 'if you get a tender that has got comprehensive operational information, then that's very helpful' [Facilities 1].

The second type of evaluation deals with unanticipated expectations, where individuals make a satisfaction judgement based on the (dis)confirmation between their underlying desires and their perceptions of performance. Expectations arise from an ideal and respondents focus on how the process should unfold. This form of evaluation relates to the process itself, where individuals compare the reality of the tender process with another imagined ideal tender process: 'It's just all very frustrating [...] compared to what it was back in the day' [Fitness 2]. The evaluation happens because there is a gap between an idealised view of how things should work and the perception of how they actually work. This may not seem important if competitive tendering is an inevitability, but it causes huge dissatisfaction amongst suppliers with the process itself. This is graphically represented in Figure 2.

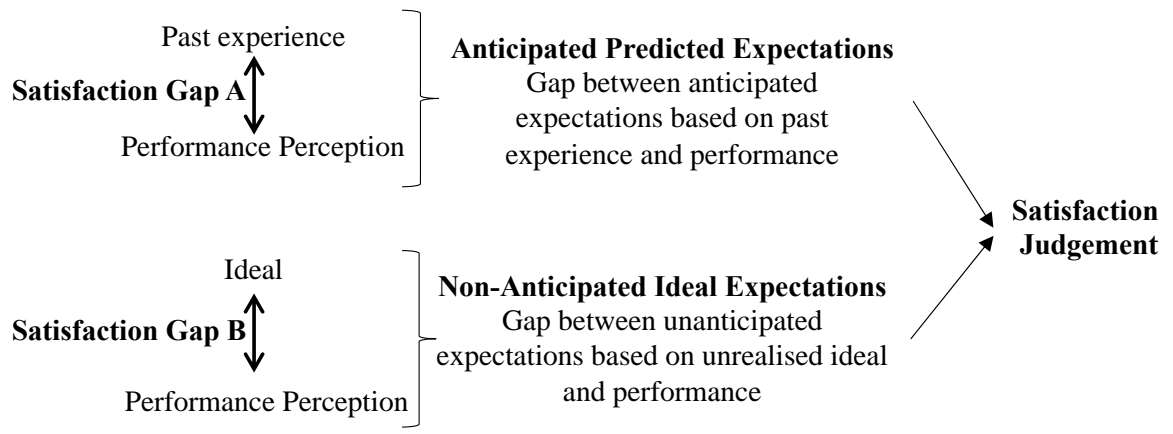

Figure 2. Dynamics of satisfaction judgements

The examples given highlight the care needed when researching the tender process. A number of respondents express satisfaction with specific tender documents as they compare favourably with others they received in the past but were dissatisfied with the tender process. Respondents stated again and again that the process was not an effective way to establish a 
buyer-supplier relationship and, given the choice, they would not use competitive tendering. The process has become entrenched as the "normal" way of doing things, leading to a general dissatisfaction with public competitive tendering as a whole rather than (solely) with specific instances of tendering activity. This analysis leads to the development of the following proposition:

P1. There are two satisfaction gaps: anticipated experience and unanticipated ideal leading to dissatisfaction judgements with the competitive tendering process.

P2. Suppliers may be satisfied with individual tender documents but will be dissatisfied due to the dissatisfaction gaps in the overall process.

\section{Quality and Satisfaction}

To answer RQ2, what quality dimensions do suppliers use to make satisfaction judgements, the full list of perceived quality dimensions that suppliers use when making satisfaction judgements is given in Appendix 1, along with first-order codes and illustrative interview quotes.

Suppliers consider several quality dimensions when evaluating their satisfaction with public sector competitive tendering. Fairness was the overarching key criteria and influenced the other perceptions of quality. Similar to Berry et al., (1994) findings on reliability, in the tender process, if the process was seen as unfair then no amount of responsiveness, clarity or relationship focus could lead to satisfaction. Fairness is the order qualifying criteria while the others are order winning. Most surprising is that winning the tender is just one of many factors, and not the main factor, that individuals use to judge their satisfaction with the process. The 
suppliers stated that they would be satisfied with a negative outcome if the process was fair, and they were given an adequate opportunity to portray their organisations.

Although research such as SERVQUAL can serve as a basis for assessing service quality, there will always be a need to interpret findings in specific contexts so that individuals may take suitable actions to address quality issues. Our research found specific tender-based quality perceptions, nearly all negative: unfairness, ambiguity, unnecessary information requirements, tender focus, relationship ignorance, unresponsiveness and outcome success and, most of such dimensions can lead to 'glitches' impacting firm performance and stakeholder value (Hoopes and Postrel 1999; Singhal and Hendricks 2002). From these findings the following propositions have been developed:

P3. Fairness is the key criterion suppliers judge the tendering process by.

P4. Suppliers will perceive a number of unsatisfactory quality dimensions including ambiguity, unnecessary information requirements, tender focus, relationship impact, unresponsiveness as well as outcome.

P5. Outcome success will not determine satisfaction if the process is perceived as unfair.

When considering the relationship between our findings in relation to research questions 1 and 2, we propose that:

P6. By comparing anticipated and ideal expectations, with the fairness and other quality dimensions of the tendering process, suppliers will make a dissatisfaction judgement 


\section{Dissatisfaction and Behaviour}

In addressing RQ3, in the behaviours resulting from (dis)satisfaction with public sector competitive tendering, consumer marketing research states that behaviour, such as the repurchasing a product or service, depends on the customer's satisfaction levels. Giving more detail to this, we found three behaviours suppliers adopt when dissatisfaction occurs as shown in table II.

Insert Table II here (Outcomes influenced by levels of (dis)satisfaction)

These outcomes are examples of supply chain glitches, e.g. mismatches between supply and demand, which result in short and long term value loss for the buying organisation (Hendricks and Singhal, 2005). We also see that dissatisfaction as a result of non-value-added activities is perceived to be one of the dominant factors responsible for glitches. Irrespective of which link in the supply chain is responsible, such glitches negatively affect profitability and value with recent literature suggesting that glitches attributed to suppliers alone are associated with a loss of 8.26 percent on the average stakeholder return (Singhal and Hendricks 2002).

These findings support the development of the following proposition:

P7. Negative outcomes of an unsatisfactory tendering process will include submitting nonresponse to tenders, poorly developed bids and relationship impacts.

However, our findings also showed that respondents focus on alternatives to tendering when they are dissatisfied with their experience in the tendering process (post-satisfaction gap). If a desired alternative exists in another setting, specifically, the private sector, respondents unanimously complain about the competitive nature of tendering, affecting their behaviour 
after the tendering process: '[They] don't even need to undertake a competition at all ... if they like what we've got they'll just buy it' [IT 1]. And 'we have the negotiated agreement with our customer, and it saves him the trouble of going out and tender' [Security 4]. In addition, these alternative ways of buying services are difficult to articulate, as they are not experienced in the public sector context, for example: '[We] deal with that through relationships rather than through responding to a process' [Security 1].

We also found that companies firstly disconfirmed the ideal process, then compared this with their past experience of tender processes, which were always bad. Once this dissatisfaction was articulated respondents viewed alternatives to the tender process as always better. Respondents stated: 'the business, in general, doesn't like the tenders' [Facilities 2], 'it's a necessary evil' [Security 4] and: 'it's just becoming a huge waste of time for all sorts of companies' [Fitness 2] leading to behaviours such as not responding to tenders, developing tenders in an incomplete or poor way and lead to mistrust and lack of commitment from the suppliers. This led to our final proposition:

P8. Dissatisfaction judgements and post-tender behaviour will be moderated by a comparison with the alternatives to the tendering process.

Combing the results culminates in a further iteration of our theoretical model of supplier satisfaction with the public sector tender process, as shown in figure 3 below. This provides more detail to our earlier conceptual model depicted in figure 1. 


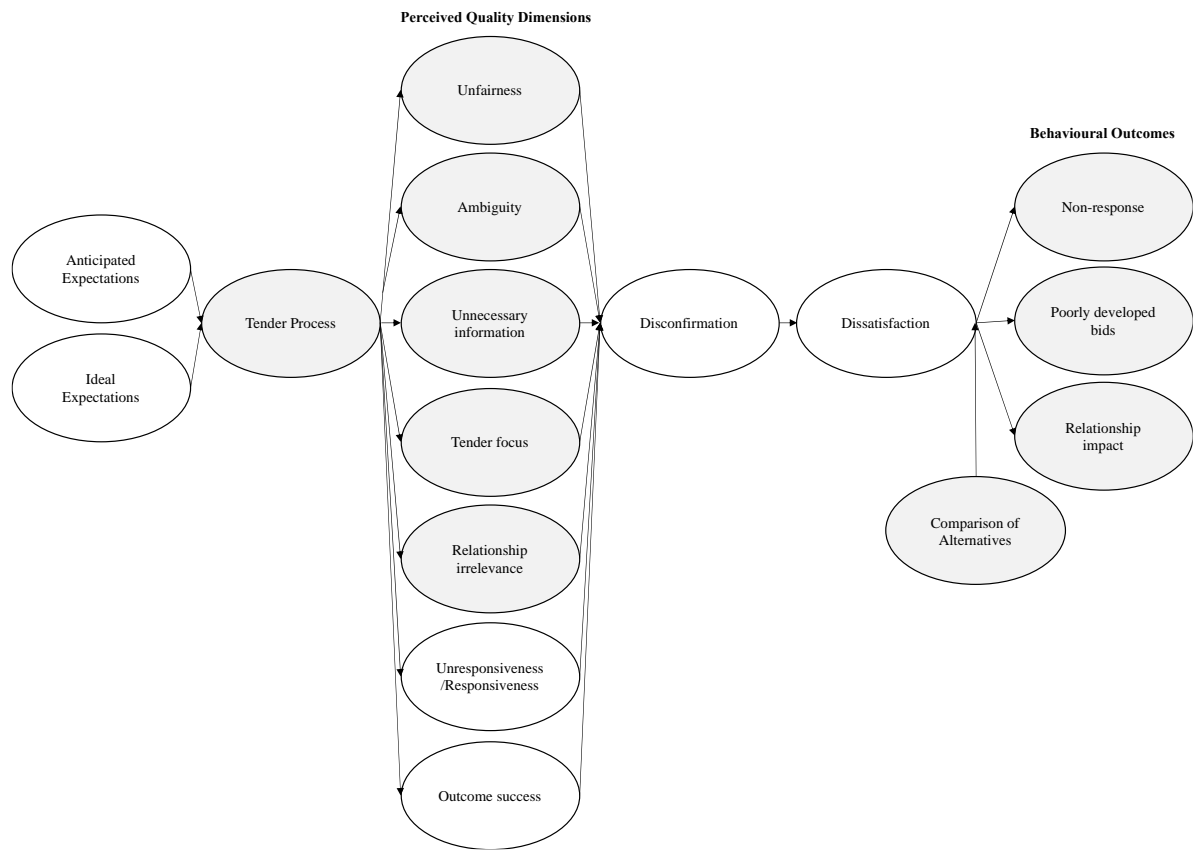

NB Shaded sections are new constructs developed inductively

Figure 3. Supplier satisfaction with the public sector competitive tendering process

This integrated model of supplier satisfaction contributes to theory by adding to and combining two theoretical areas (satisfaction and service quality) in a novel way and in a unique setting. We show that suppliers have two types of expectations of the tendering process predictive where they have anticipated expectations based on previous experiences, idealised where they compare it to an ideal tender. These expectations influence how the suppliers perceive a number of quality dimensions. Our findings show an extension to the SERQUAL and INDSERV frameworks and provide context-specific quality dimensions that are analogous to some dimensions (unresponsiveness to responsiveness (SERVQUAL) and soft process quality (INDSERV) but mainly find new constructs, with fairness the key quality construct. Suppliers then make dissatisfaction judgments, and where tender processes are weighed against private 
sector processes, result in specific behaviours with significant consequences for buying organisations.

\section{Discussion}

This research set out to investigate how satisfied suppliers are with the public sector tendering process, what expectations they have, how they judge the quality of the tendering process and how the experience affects their behaviour.

\section{Theoretical implications}

In terms of theoretical contributions, we took a unique approach compared to much public procurement literature, which focuses, almost exclusively, on buying organisations. We adapted concepts from satisfaction theory used in the marketing and consumer fields, which evaluate the impact of satisfaction on the behaviours of those engaged in consuming the service. By viewing the competitive tendering process as a service encounter, we see that supplier dissatisfaction results from a range of quality dimensions causing changes in behaviour with negative ramifications for both individual buying organisations and the public sector. We also provide extensions to the public procurement literature by looking specifically at the tendering process, rather than other for example politically-driven factors and show the differences between anticipated and ideal expectations, providing new and comprehensive quality dimensions that impact upon judgements, and by showing the behaviours that result from gaps in satisfaction.

Managerial implications 
For public sector buyers in the tendering process, there are several recommendations related to each aspect of the model. With regards to supplier expectations, buyers could challenge idealised expectations through 'Meet the Buyer' events, where suppliers get a realistic idea about the tendering process. By having consistently good experiences with the public sector, supplier's predictive expectations can be raised as well. As regards to perceived quality dimensions of the tendering process, it is within the buyer's purview to raise the quality of the tendering experience and avoid glitches (Hoopes and Postrel 1999). Having accurate relevant information shared through a common electronic portal is helpful, but opportunities for dialogue during the tender process are limited and often conducted by e-mail. Therefore, buyers need to plan buyer-supplier relationship-building early in the process, engaging with suppliers, involving end-users and service managers prior to the tendering process. Above all buyers must be courteous and fair and give suppliers the opportunity to showcase how their organisation can meet buyer needs. Public sector buyers would do well to remember that suppliers have a choice in which organisations they sell to. Buyers are not able to influence whether they tender or not (i.e. effectiveness) as this is under the control of policymakers. Therefore, the buyer should focus on improving their specific tendering processes (i.e. efficiency). These improvements should also examine the different dimensions of quality as perceived by suppliers. Table III suggests improvements, derived from the data, where suppliers identified best practice, ideal or alternative behaviours.

Insert Table III here (Quality improvement suggestions)

From the perspective of suppliers to the public sector, they are engaged with multiple buyers and do not make their satisfaction judgements solely on their current tender process, but across a range of experiences. If they consistently have poor experiences with different 
public sector buyers, then dissatisfaction could be magnified. Higher levels of supplier dissatisfaction will result in a reduced number of suppliers who are prepared to respond to individual tenders and, therefore, competition will be limited. The effect of this would be an increase in unit pricing, as suppliers feel less pressure to offer the most competitive pricing. Adding to the possibility of glitches, this will also mean that potentially superior offerings in terms of quality will not be received by the buying organisations due to the smaller number of suppliers responding. Given that public sector buyers and government are influential stakeholders for suppliers (Wu et al., 2014), they ignore supplier satisfaction in the tendering process at their peril, as costs of rectification are likely to be high.

For public procurement policymakers, this is an opportune time for the sector to revisit the competitive tendering process, as the UK leaves the EU, new trade laws are established in the US and national governments deal with ever-increasing financial demands on their expenditure. The research found several factors that are within a buying organisation's control and that can be changed to increase supplier satisfaction with the competitive tendering process. It is important to note that these improvements can be made within the confines of the legal and organisational requirements of the current competitive tendering framework. If policymakers can incorporate these factors into tendering process policy and guidelines, it will benefit buyer-supplier relationships, contribute to the efficiency agenda and provide greater value for money for citizens and taxpayers.

Ineffective management of supply chains significantly harms stakeholder value (Singhal and Hendricks 2002). Thus, other practical recommendations for reducing or avoiding the possibility of future glitches include developing policy guidance to encourage greater levels of personal engagement between buyers and suppliers, and earlier involvement of end-users, service managers and other stakeholders in the buying organisation, to help provide a closer link between the tendering activities and the final service that will be provided. There should 
also be a greater use of regional and national centralised databases of information, as a key quality dimension was the repetition of the same information for different public bodies.

\section{Conclusion}

This article set out to contribute to the literature on public sector competitive tendering and addresses a burgeoning interest in how to make public sector buying organisations more attractive to their suppliers. The study recognises the lack of research on the supplier perspective in this critical area of government spend and, using theories and models from the satisfaction and service quality literature to position suppliers as service users of competitive tendering, it has generated novel insights into the phenomenon. This research has resulted in the development of a model of supplier satisfaction that links expectation dynamics, service quality dimensions and behaviour resulting from satisfaction judgements. In addition, by establishing the serious ramifications of poor levels of satisfaction, it has provided a set of empirically-grounded recommendations and suggestions for managers and policymakers that can be used to improve both the efficiency (doing things in the right way) and effectiveness (doing the right things) of how public sector organisations buy services.

This exploratory research is intended to open the discussion of supplier satisfaction with tendering processes and a number of future research opportunities have been identified. As a suggested next step, we would encourage the measurement of the strength of the different dimensions of service quality to show to which outcomes of the tendering process they are linked. For example, which dimensions, other than fairness, have a greater effect on supplier satisfaction, for instance, improving information accuracy or establishing early relationships with suppliers and also considering how these dimensions interact? Doing this would allow buying organisations to target specific areas of the tendering process in introducing process and practice change. In addition, using the literature on supply chain glitches as a basis, further 
research could focus on the financial impacts of unreliability and unresponsiveness in this aspect of supply chain management. As the main focus of previous literature in this area (e.g. Singhal and Hendricks, 2002) is on the impact of glitches on shareholder value, it would be useful to widen the scope of this to consider a wider range of factors that are specific to different public sector settings.

Although multiple supplier types were involved in this research and the sample was representative across several service types, the study is limited to UK-centred organisations, which we attempted to mitigate by interviewing international suppliers. The similar underlying principles of public procurement across the EU, US and internationally, and comparable tender processes and documentation, suggest the findings may have a resonance for public procurement in other countries, and the model could be tested with public procurers and suppliers outside of the UK.

\section{References}

Anderson, E. W., and M. W. Sullivan. 1993. "The Antecedents and Consequences of Customer Satisfaction for Firms.” Marketing Science 12 (2), pp 125-133.

Argyle, M., 1967. “The Social Psychology of Social Change”. Social Theory and Economic Change, pp.87-101. BBC. 2012. "West coast mainline deal scrapped after contract flaws discovered." BBC News, 3rd October. http://www.bbc.co.uk/news/business-19809717

Benton, W. C., and Michael Maloni. 2005. "The Influence of Power Driven Buyer/Seller Relationships on Supply Chain Satisfaction." Journal of Operations Management 23(1), pp 1-22.

Bergman, M., and S. Lundberg, S. 2013. "Tender Evaluation and Supplier Selection Methods in Public Procurement.” Journal of Purchasing and Supply Management 19(2), pp 73-83.

Berry, Leonard L., Anantharanthan Parasuraman, and Valerie A. Zeithaml. 1994. "Improving Service Quality in America: Lessons Learned." Academy of Management Perspectives 8(2), pp 32-45.

Boulding, W., R. Staelin, A. Kalra, and V.A. Zeithaml. 1993. “A Dynamic Process Model of Service Quality: From Expectations to Behavioral Intentions.” Journal of Marketing Research 30(1), pp 7-18. 
Boyt, T., and M. Harvey. 1997. "Classification of Industrial Services: A Model with Strategic Implications." Industrial Marketing Management 26(4), pp 291-300.

Cadden, T., D. Marshall, P. Humphreys, and Y. Yang. 2015. “Old Habits Die Hard: Exploring the Effect of Supply Chain Dependency and Culture on Performance Outcomes and Relationship Satisfaction.” Production Planning and Control 26(1), pp 53-77.

Cavana, R. Y., B. L. Delahaye, and U. Sekaran. 2001. Applied Business Research: Qualitative and Quantitative Methods. John Wiley \& Sons Australia.

Cho, Y., R. Hiltz, and J.Fjermestad. 2002. "The Effects of Post-Purchase Evaluation Factors on Online versus Offline Customer Complaining Behavior: Implications for Customer Loyalty,” in NA. In S. M. Broniarczyk and K. Nakamoto (Eds.), Advances in Consumer Research 29, Valdosta, GA: Association for Consumer Research, pp 318-326.

Churchill Jr, G.A., and C. Surprenant. 1982. "An Investigation into the Determinants of Customer Satisfaction.” Journal of Marketing Research Nov(1), pp 491-504.

Cornelissen, J. 2017 “Editor's comments: Developing Propositions, a Process Model, or a Typology? Addressing the Challenges of Writing Theory Without a Boilerplate." Academy of Management Review 42(1), pp 1-9.

Delbridge, R., and P. C. Fiss. 2013. "Editors' Comments: Styles of Theorizing and the Social Organization of Knowledge.” Academy of Management Review 38(3), pp 325-331.

Di Mauro, C., Ancarani, A. and Hartley, T. (2020), "Unravelling SMEs' participation and success in public procurement", Journal of Public Procurement, Vol. 20 No. 4, pp. 377-401. https://doi.org/10.1108/JOPP-032018-0013.

Eckerd, A. and A. Girth 2017. "Designing the Buyer-Supplier Contract For Risk Management: Assessing Complexity and Mission Criticality." Journal of Supply Chain Management 53(3), pp 60-75.

Emerson, R M (1976). "Social Exchange Theory". Annual Review of Sociology 2: 335-362

Essig, M., and M. Amann. 2009. “Supplier Satisfaction: Conceptual Basics and Explorative Findings.” Journal of Purchasing and Supply Management 15(2), pp 103-113.

European Commission. 2018. Public Procurement, http://ec.europa.eu/growth/single-market/publicprocurement/index_en.htm.

Europa, Accessed $14^{\text {th }}$ December 2018. www.ec.europa.eu

Federation of Small Businesses Biannual Survey. 2008.

https://www.fsb.org.uk/LegacySitePath/policy/assets/fsb\%20icm\%20annual\%20survey\%20uk.pdf 
Fife, W. 2005. Doing Fieldwork: Ethnographic Methods for Research in Developing Countries and Beyond. New York: Palgrave Macmillan.

Forrester, A., A. Till, J. Senior, and J. Shaw. 2015. “Competitive Tendering and Offender Health Services.” The Lancet Psychiatry 2(10), pp 859-861.

Giese, Joan L., and Joseph A. Cote. 2000. "Defining Consumer Satisfaction." Academy of Marketing Science Review 1(1), pp 1-22.

Gounaris, S. 2005. "Measuring Service Quality in B2B Services: An Evaluation of the SERVQUAL scale." Journal of Service Marketing 19(6-7), pp 421-436.

Griffith, D.A., Harvey, M.G. and Lusch, R.F., (2006). "Social Exchange in Supply Chain Relationships: The Resulting Benefits of Procedural and Distributive Justice.” Journal of Operations Management 24(2), pp.8598.

Hald, K., C. Cordon, and T. Vollmann. 2009. "Towards an Understanding of Attraction in Buyer-Supplier Relationships.” Industrial Marketing Management 38(8), pp 960-970.

Hallowell, R. 1996. "The Relationships of Customer Satisfaction, Customer Loyalty, and Profitability: An Empirical Study.” International Journal of Service Industry Management 7(1), pp 27-42.

Halstead, D., and T. J. Page. 1992. "The Effects of Satisfaction and Complaining Behavior on Consumer Repurchase Intentions.” Journal of Consumer Satisfaction, Dissatisfaction and Complaining Behavior 5(1), pp 1-11.

Harland, C., J. Telgen, G. Callender, R. Grimm, and A. Patrucco. 2019. "Implementing Government Policy n Supply Chains: An International Coproduction Study of Public Procurement.” Journal of Supply Chain Management, 55(2), pp 6-25.

Hendricks, K.B. and Singhal, V.R. 2005. "Association Between Supply Chain Glitches and Operating Performance.” Management Science, 51(5), pp 695-711.

Homans, G. (1961). Social Behavior: Its Elementary Forms. New York: Harcourt Brace Jovanovich.

Hoopes, D. G., and S. Postrel. 1999. "Shared knowledge, "glitches" and product development performance." Strategic Management Journal, 20(9), pp 837-865.

Hsu, F-M., T-Y. Chen, and S. Wang, 2009. "Efficiency and Satisfaction of Electronic Records Management Systems in E-Government in Taiwan.” Electronic Library 27(3), pp 461-473.

Jiang, B, G. Reinhardt, and S. T Young. 2008. "BOCOG's Outsourcing Contracts: The Vendor's Perspective." Omega 36(6), pp 941-949. 
Khalifa M. and V. Liu. 2003. "Determinants of Satisfaction at Different Adoption Stages of Internet-Based Services.” Journal of the Association for Information Systems 4(5), pp 206-232.

Kleemann, F. C., and M. Essig. 2013. “A Providers’ Perspective on Supplier Relationships In Performance-Based Contracting." Journal of Purchasing and Supply Management 19(3), pp 185-198.

Kotler P., G., Armstrong, J. Saunders, and V. Wong, 2002. Principles of Marketing, 3rd Edition, Prentice Hall: Europe.

Lambe, C. J.; Wittmann, C. M.; and Spekman, R. E. (2001). "Social Exchange Theory and Research on Businessto-Business Relational Exchange". Journal of Business-to-Business Marketing. 8 (3): 1-36.

Land, Martin J., and Gerard J. C. Gaalman. 2009. "Production Planning and Control in SMEs: Time for Change." Production Planning and Control 20(7), pp 548-558.

Lega, F., M. Marsilio, and S. Villa. 2013. “An Evaluation Framework for Measuring Supply Chain Performance in the Public Healthcare Sector: Evidence from the Italian NHS.” Production Planning and Control, 24(10-11), pp 931-947.

Loader, K. 2013. "Is Public Procurement a Successful Small Business Support Policy? A Review of the Evidence." Environment and Planning C: Government and Policy 3(1), pp 39-55.

Loader, K. 2015. "SME Suppliers and the Challenge of Public Procurement: Evidence Revealed by a UK Government Online Feedback Facility.” Journal of Purchasing and Supply Management 21(2), pp 103-112.

Mateus, R., J. A. Ferreira, and J. Carreira. 2010. "Full Disclosure of Tender Evaluation Models: Background and Application in Portuguese Public Procurement.” Journal of Purchasing and Supply Management 16(3), pp 206-215.

Maunu, S. 2003. Supplier Satisfaction: The Concept and Measurement System. Oulu, Finland: University Press, Oulu.

McDougall, G., and T. Levesque. 2006. "Customer Satisfaction with Services: Putting Perceived Value into the Equation.” Journal of Services Marketing, 14(5), pp 392-410.

Meuter, M., A. Ostrom, R. Roundtree, and M. Bitner. 2000. "Self-Service Technologies: Understanding Customer Satisfaction with Technology-Based Service Encounters.” Journal of Marketing, 64(3), pp 50-64.

Mohr, L. 1982. Explaining Organizational Behavior. US: Jossey-Bass.

Mouwen, A., and P. Rietveld. 2013 "Does Competitive Tendering Improve Customer Satisfaction with Public Transport? A Case Study for the Netherlands.” Transportation Research Part A: Policy and Practice 51(May), pp 29-45. 
Nakibin, D. I. Ismail, M. Marimuthu, and I. Abu-Jarad. 2011. “The Impact of Firm Reputation on Customers' Responses to Service Failure: The Role of Failure Attributions.” Business Strategy Series 12(1), pp 19-29. NIGP. 2013. https://issuu.com/nigp/docs/nigp2013annualreport

OECD. 2016. Public Procurement Toolbox. DOI: http://www.oecd.org/governance/procurement/toolbox/ Accessed $1^{\text {st }}$ May 2018.

OECD. 2017. Government at a Glance 2017. OECD Publishing, Paris. DOI: https://doi.org/10.1787/gov_glance2017-59-en. Accessed $1^{\text {st }}$ May 2018.

OECD. 2018. Recommendation of the Council on Public Procurement. Accessed $1^{\text {st }}$ May 2018.

Oliver, R. 1981. "Measurement and Evaluation of Satisfaction Process in Retail Setting." Journal of Retailing 57(Fall): 25-48.

Parasuraman, A, V. Zeithaml, and L. Berry. 1988. "SERVQUAL: A Multiple-Item Scale for Measuring Consumer Perceptions of Service Quality.” Journal of Retailing 64(1), pp 12-25.

Parikka-Alhola, K. and Nissinen, A. (2012), "Environmental impacts and the most economically advantageous tender in public procurement", Journal of Public Procurement, Vol. 12 No. 1, pp. 43-80. https://doi.org/10.1108/JOPP-12-01-2012-B002

Pedraza-Acosta, I., A. Pilkington, and D. Barnes. 2016. "Production Systems and Supplier Selection: A MultiPhase Process Model.” Production Planning and Control 27(9), pp 717-726.

Pickernell D., A. Kay, G. Packham, and C. Miller. 2011. "Competing Agendas in Public Procurement: An Empirical Analysis of Opportunities and Limits in the UK for SMEs." Environmental Planning C: Government Policy 29(4), pp 641-658.

Prakash, V. 1984. "Validity and Reliability of the Confirmation of Expectations Paradigm as a Determinant of Consumer Satisfaction.” Journal of the Academy of Marketing Science 12(4), pp 63-76.

Purchase, S., T. Goh, and K. Dooley. 2009. "Supplier Perceived Value: Differences Between Business-toBusiness and Business-to-Government Relationships.“ Journal of Purchasing and Supply Management, 15, pp 3-11.

Ramsay, J. 2005. “The Real Meaning of Value in Trading Relationships.” International Journal Of Operations And Production Management, 25(6), pp 549-565.

Ramsay, J., and B. Wagner. 2009. “Organizational Supplying Behaviour: Understanding Supplier Needs, Wants and Preferences." Journal of Purchasing and Supply Management 15(2), pp 127-138. 
Ramsay, J., B. Wagner, and S. Kelly. 2013. "Purchase Offering Quality: The Effects of Buyer Behaviour on Organizational Supplying Behaviour." International Journal of Operations and Production Management 33(10), pp 1260-1282.

Schiele, H., R. Calvi, and M. Gibbert. 2012. "Customer Attractiveness, Supplier Satisfaction and Preferred Customer Status: Introduction, Definitions and an Overarching Framework." Industrial Marketing Management 41(8), pp 1178-1185.

Schiele, H. 2020, "Comparing public and private organisations in their quest to become a preferred customer of suppliers", Journal of Public Procurement, 20(2), pp. 119-144.

Schiffman, L., and L. Kanuk. 1978. Consumer Behavior. Englewood Cliffs, NJ: Prentice-Hall.

Singhal, V. R. and K. B. Hendricks, 2002. How Supply Chain Glitches Torpedo Shareholder Value. Supply Chain Management Review, 6(1), pp. 18-24.

Stanworth, J. 2012. "Deep Supply Relationships: Influencing Outcomes by Managing Supply Service Quality." Production Planning and Control 23(7), pp 541-552.

Stilger, P.S., J. Siderius, and E.M.V.Raaij. 2017. "A comparative study of formulas for choosing the economically most advantageous tender", Journal of Public Procurement, 17(1), pp. 89-125.

Swan, J., F. Trawick, and M. Carroll. 1982. "Satisfaction Related to Predictive, Desired Expectations: A Field Study", in H. Hunt and R. Day, (eds.). New Findings on Consumer Satisfaction and Complaining. Bloomington, Indiana: Indiana University Press, pp 15-22.

Tadelis, S., and P. Bajari, 2006. "Incentives and Award Procedures: Competitive Tendering vs. Negotiations in Procurement. Handbook of Procurement: pp 121-139.

Tam, J. 2004 “Customer Satisfaction, Service Quality and Perceived Value: An Integrative Model.” Journal of Marketing Management 20(7-8), pp 897-917.

Thibaut, N. and Kelley, H. (1959). The Social Psychology of Groups. New York Wiley

Tse, D., and Wilton, P. 1988. "Models of Consumer Satisfaction: An Extension.” Journal of Marketing Research, 25(May), pp 204-212.

USA Spending. 2018. www.usaspending.gov Accessed $8^{\text {th }}$ January 2018.

Uyarra, E., and K. Flanagan, 2010 "Understanding the Innovation Impacts of Public Procurement." European Planning Studies 18(1), pp 123-143.

Van Weele, A. 2010. Purchasing and Supply Chain Management: Analysis, Strategy, Planning and Practice. EMEA, Cengage Learning. 
Walker, H. F. Schotanus, E. Bakker, and C. Harland. 2013. "Collaborative procurement: a relational view of buyer-buyer relationships.” Public Administration Review, 73(4), pp 588-598.

White, A. 2014. "Post-Crisis Policing and Public-Private Partnerships: The Case of Lincolnshire Police and G4S. British Journal of Criminology 54(6), pp 1002-1022.

Wu, Z., L. Ellram, and R. Schuchard. 2014 "Understanding the role of government and buyers in supplier energy efficiency initiatives.” Journal of Supply Chain Management 50(2), pp 84-105.

Yin, R. 2008. Case Study Research: Design and Methods. Fourth Edition. Thousand Oaks, CA: Sage Publications. Zeithaml, V., L. Berry, and A. Parasuraman. 1993. "The Nature and Determinants of Customer Expectations of Service." Journal of the Academy of Marketing Science, 21(1), pp 1-12. 
Appendix 1. Perceived quality dimensions in competitive tendering in the public sector

Perceived

quality

dimension

Unfairness

First-order codes

Example quotations

Unfair/unethical process

You've always got the suspicion there that really it doesn't matter what you

put in there because it's whoever's cheapest at the end of the day [Building 1

Because we find in some instances that their minds are already made up with who they want and so a tender is really written in the favour of that particular company [Fitness 1] The questions are vague and they're vague to enable them to score them in a way that they see fit, to ensure that the people they want to win is actually going to secure it [Fitness 2] You could almost bet money on who was going to win it [Security 5]

Unfair information distribution Where tenders fall down is the correct information getting fed to anybody going into a tender [Facilities 2]

Lack of time

A chance to put in an alternative bid, however, because of the time scales of, you know, in the public sector, there's often not enough opportunity [Security 5] The coincidence of them coming out during holiday periods, so their staff released them as they go off on Christmas leave and...they'll give us maybe a month to pull together something which will be issued around the Christmas period and due in for the 1st January which obviously puts our staff under stress [Consultancy 2] There are other ones where halfway through, you've got about a week to go, and then you get some more information through and...this bit here we don't need, what we need instead is this. So the goalposts change halfway through the process [Security 2] We just kept getting these letters saying 'oh, it's been delayed, it's been delayed, I was expecting someone to write me an email saying, you know, the dog's eaten my homework or something, but it really felt like that. Finally, they issued the tender the following November giving us three weeks to respond and it's just like 'forget it'. Forget it! [Security 5]

Ambiguity Illogic of documentation Very often they kind of tend to jump around a little bit [Security 2] Some tender documents that come out that are not particularly logical and...you're going backwards and forwards with it [Security 3] you've got to really read them several times to confirm what the client is after [Security 7]

Requirement ambiguity Sometimes you have to read between the lines when you see areas of tenders [Facilities 1] makes it more difficult for you to highlight the areas where you think you can bring real benefit [Facilities 1] so often you get an invitation to tender that's used for virtually any types of goods or services, and they can be very, very tricky to answer, some of them, because they're not particularly relevant to what we do [Facilities 3] why we're not winning those tenders is because we've answered a question slightly incorrectly, because we didn't understand it [Fitness 2] the questions are vague [Fitness 2] There's nothing more frustrating than getting a tender through where they want you to give them charge rates but we haven't got any pay rates [Security 2] Equally you can't visualise what the site might look like [Security 3] the terminology being used is a little out of date [Security 4] it's not clear within the documentation whether this is a completely new requirement [Security 4 ] because if we can't see what we're doing we can't put forward properly [Security 5]

Use of ambiguous criteria We hadn't been trading long enough to get the maximum points on the company history or we didn't have a large enough turnover to score the best in the financial profile [Facilities 1] if you're not quite on that range of turnover then you're disqualified [Security 3]

Evaluation ambiguity When it comes to the evaluation, we're only going to look at A and B [Consultancy 1] My perception of quality and your perception of quality may be entirely different [Fitness 2] The people making the decision on a tender, whether it be this one or anybody else, may not necessarily be the end-user [Security 6] We often get tenders that have been written by people who clearly don't understand exactly the services that they're procuring [Facilities 3] 
Unnecessary information

Tender Focus Tender focus, not service focus

Lack of capability focus

Relationship Relationship irrelevant Ignored

Past experience irrelevant

Unresponsive Late communication or Responsive requirements

Repetitive requirements

Those policies aren't looked into, they're just kicked...so it just seems a bit pointless really [Building 1] Probably over a hundred grand each time we're bidding [Consultancy 2] so often you get an invitation to tender that's used for virtually any types of goods or services, and they can be very, very tricky to answer, some of them, because they're not particularly relevant to what we do [Facilities 3] Sometimes there's a lot of overkill on some of the tenders [Fitness 1] They're very wordy....about one hundred and sixty pages of tende specification sheets that came out [Fitness 2] When a small company, you know, we try and be environmentally friendly and operate in that genre but you don't always document everything that you do [ [ Lab 1] As long as you've got a health and safety policy and a health a safety officer, and I don't think half of them read it they just ask for it [Security 1]

amazing how many tenders just repeat themselves, you know, particularly around the health and safety information [Building 1] The depth of questioning can be quite erm quite lengthy and involved. Very often we do repeat ourselves from one question to the next [and] find one statement for ourselves covers several questions [ L L a b 1 1$]$ Just to do it once rather than do it half a dozen times [Medical 1]

It's just an exercise to win the tender it isn't really an exercise on how it's going to be delivered and managed [Building 1] makes it more difficult for you to highlight the areas where you think you can bring real benefit

[Facilities 1] Whereas there isn't a great deal of questions about the most important thing which is about the service that you're providing [Security 3] I don't think it's applicable in some cases to some of the requirements of the contract [Security 3] because they have a much more administrative task than actually getting to the crux of the solution [Security 5] you're limited on the information you can write down [Security 8 ]

makes it more difficult for you to highlight the areas where you think you can bring real benefit [Facilities 1] Doesn't seem to, on a lot of them, ever be an opportunity to be able to put in sort of alternative ideas [Security 3] no one's asked what sort of innovations can you bring to the service? [Security 8 ]

Just get a bland notification and then you've got to log into the hub [Consultancy 2] I'm dealing with a software that I'm not familiar with and having to do filling in of all the correct boxes [Medical 1] What I'd like to see is a personal touch, I think it would be fairly good to get one to one meetings with your potential, or the people who are going to tender [Security 8 ] Because there's no score for the value that the past company has delivered [Security 9]

The coincidence of them coming out during holiday periods, so their staff released them as they go off on Christmas leave and...they'll give us maybe a month to pull together something which will be issued around the Christmas period and due in for the 1st January which obviously puts our staff under stress [Consultancy 2] There are other ones where halfway through, you've got about a week to go, and then you get some more information through and ... this bit here we don't need, what we need instead is this. So the goalposts change halfway through the process [Security 2] The Tender came in and we were really pleased as we had got through all of those pages, and then it said you must have a certain turnover and this is what your turnover must be, and it wasn't us, so we were like well after all that, we couldn't do it anyway [Security 3] We just kept getting these letters saying 'oh, it's been delayed, it's been delayed, I was expecting someone to write me an email saying, you know, the dog's eaten my homework or something, but it really felt like that. Finally, they issued the tender the following November giving us three weeks to respond [Security 5]

Lack of outcome

We find that a lot we send off we don't get a reply whether we've been successful or not [Security 1$]$ 


\section{Responsive}

You can get an instant response to what you're really trying to get to the

Outcome

Supplier Success

bottom of [Security 8 ]

Obviously, the most important thing is yes to actually be successful [Security

3] the desire to win [Security 4]

NB shaded area only positive statement in the interviews 